\title{
Smoking, DNA Adducts and Number of Risk DNA Repair Alleles in Lung Cancer Cases, in Subjects with Benign Lung Diseases and in Controls
}

\author{
Marco Peluso, ${ }^{1}$ Armelle Munnia, ${ }^{1}$ Sara Piro, ${ }^{1}$ Alessandra Armillis, ${ }^{1}$ Marcello Ceppi, ${ }^{2}$ \\ Giuseppe Matullo, ${ }^{3,4}$ and Riccardo Puntoni ${ }^{2}$ \\ ${ }^{1}$ Cancer Risk Factor Branch, Analytical and Biomolecular Cytology Unit, ISPO-Cancer Prevention and Research Institute, \\ Via Cosimo il Vecchio N.2, 50139 Florence, Italy \\ ${ }^{2}$ Molecular Epidemiology Unit, National Cancer Research Institute, 16132 Genoa, Italy \\ ${ }^{3}$ Department of Genetics, Biology and Biochemistry, Faculty of Medicine and Surgery, University of Turin, 10124 Turin, Italy \\ ${ }^{4}$ Section of Epidemiology, ISI Foundation-Institute for Scientific Interchange, Villa Gualino, 10133 Turin, Italy
}

Correspondence should be addressed to Marco Peluso,m.peluso@ispo.toscana.it

Received 14 May 2010; Revised 8 July 2010; Accepted 28 July 2010

Academic Editor: Shigenori Iwai

Copyright () 2010 Marco Peluso et al. This is an open access article distributed under the Creative Commons Attribution License, which permits unrestricted use, distribution, and reproduction in any medium, provided the original work is properly cited.

Smoke constituents can induce DNA adducts that cause mutations and lead to lung cancer. We have analyzed DNA adducts and polymorphisms in two DNA repair genes, for example, XRCC1 Arg194Trp and Arg399Gln genes and XRCC3 Thr241Met gene, in 34 lung cancer cases in respect to 30 subjects with benign lung cancer disease and 40 healthy controls. When the study population was categorized in base to the number of risk alleles, adducts were significantly increased in individuals bearing 3-4 risk alleles $(\mathrm{OR}=4.195 \%$ C.I. $1.28-13.09, P=.009)$. A significant association with smoking was noticed in smokers for more than 40 years carrying 3-4 risk alleles $(\mathrm{OR}=36.38,95 \%$ C.I. $1.17-1132.84, P=.040)$. A not statistically significant increment of lung cancer risk was observed in the same group $(\mathrm{OR}=4.54,95 \%$ C.I. $0.33-62.93, P=.259)$. Our results suggest that the analysis of the number of risk alleles predicts the interindividual variation in DNA adducts of smokers and lung cancer cases.

\section{Introduction}

Lung cancer is a leading cause of cancer death in the world [1]. Advances in the treatment of locally advanced lung cancer had no impact on overall 5-year survival rates from this disease that remains only of $15 \%$. Although the rates of lung cancer mortality have started to decrease in countries where smoking habits have been modified, the projections are not optimistic because of the recent surge in tobacco consumption among young people. In addition, even if smoking habits could be modified significantly, the long lag time between peak of tobacco consumption and the development of lung cancer will assure a long life for this epidemic.

The role of tobacco smoking in the aetiology of lung cancer has been widely evaluated [2]. Many compounds present in the smoke of cigarettes, such as the polycyclic aromatic hydrocarbons (PAH), induce DNA adducts after metabolic activation [3]. Unrepaired DNA adducts can cause mutations, including mutational hot spots in p53 tumour suppressor gene [4], and lead to unregulated cell growth and cancer. Increased DNA adduct levels have been suggested to be predictive of lung cancer risk, reflecting both the environmental exposure to carcinogens than individual susceptibility [5-8].

It has been hypothesized that interindividual difference in lung cancer risk may be due to differences in DNA repair. In support of this hypothesis, different studies have indicated that DNA variation in DNA repair genes may influence cancer susceptibility [9]. Our group has conducted a number of studies that have shown associations between DNA polymorphisms in DNA repair genes, mainly in XRCC1 (Xray repair cross complementing) and XRCC 3 genes, cancer, and/or DNA adducts [10-14] and unpublished results. 
Thus, we have decided to extend our analysis to the individuals included in a lung cancer case-control study.

In this study, we have analyzed the levels of DNA adducts and DNA polymorphisms in two DNA repair genes, for example, XRCC1 Arg194Trp and XRCC1 Arg399Gln, and XRCC3 Thr241Met polymorphisms, representing the base excision repair (BER) and the double-strand breaks repair (DSB) pathways, in lung cancer cases in respect to individuals with benign lung disease and to healthy controls. Then, we decided to investigate the combination of the variant allele/s of XRCC1 Arg194Trp and Arg399Gln polymorphisms with the wild type allele of XRCC3 Thr241Met. The analysis of the effects of different combinations of DNA repair polymorphisms on DNA adducts has been done under the assumption that the combination of polymorphisms can have additive or more than additive effects on DNA adduct formation.

\section{Materials and Methods}

2.1. Study Population. Peripheral blood samples were collected, after written informed consent to participate in the present study, from 34 nonsmall cell lung cancer patients (26 males and 8 females, mean age 63.4 years) and from 30 (22 males and 8 females, mean age 63.5 years) subjects with benign lung diseases admitted to the National Cancer Institute and San Martino Hospital, Genoa, Italy. 40 controls (25 males and 15 females, mean age 63.4 years) were recruited from a group of blood donors. Lung cancer cases were asked to participate in the study after the diagnosis, but before radio and chemotherapy. The group of benign lung diseases was formed by subjects affected by Chronic Obstructive Pulmonary Disease (COPD), asthma, and pneumoconiosis. A standard questionnaire was administered to all volunteers by personal interview at the time of blood collection. Smoking status was defined as smoker, within the last year, former smoker, at least one year before diagnosis, and nonsmoker.

2.2. DNA Adduct and Polymorphism Analyses. Peripheral blood lymphocytes (PBLs) were separated from $5 \mathrm{~mL}$ freshly collected whole blood by centrifugation on a Ficoll gradient. PBL DNA was extracted and purified using a method that requires RNA and protein digestion and extraction with organic solvents [13]. DNA samples were stored at $-80^{\circ} \mathrm{C}$ until laboratory analysis. PBL DNA adducts were analysed using the nuclease $\mathrm{P} 1$ modification of the ${ }^{32} \mathrm{P}$ postlabelling technique [13]. DNA samples $(1-5 \mu \mathrm{g})$ were digested with micrococcal nuclease $(32.17 \mathrm{mU})$ and spleen phosphodiesterase $(21.6 \mathrm{mU})$. Hydrolized DNA was treated with nuclease P1 (110 mU) for 30'. The nuclease P1 resistant DNA samples were then labelled by incubation with $25 \mu \mathrm{Ci}$ of carrier-free $\left[\gamma^{32} \mathrm{P}\right]$ ATP $(3000 \mathrm{Ci} / \mathrm{mM})$ and T4polynucleotide kinase $(112.5 \mathrm{mU})$. The obtained ${ }^{32} \mathrm{P}$-labelled samples were analysed using $1.0 \mathrm{M}$ sodium phosphate, $\mathrm{pH}$ 6.8. DNA adduct resolution was achieved using 4.0 M lithium formate, $7.5 \mathrm{M}$ urea, $\mathrm{pH} 3.5$ and $0.65 \mathrm{M}$ lithium chloride, 0.45 M Tris base, 7.7 M urea, $\mathrm{pH}$ 8.0. Chromatograms were finally developed using $1.7 \mathrm{M}$ sodium phosphate $\mathrm{pH}$ 5.0. Detection and quantification of PBL DNA adducts and normal nucleotides ( $\mathrm{nn}$ ) were obtained by storage phosphor imaging techniques employing intensifying screens [15]. After background subtraction, the levels of DNA adducts were expressed such as relative adduct labelling (RAL) $=$ screen pixel in adducted nucleotides/screen pixel in nn.

Polymerase Chain Reaction followed by enzymatic digestion was used for the genotyping of XRCC1 Arg194Trp and Arg399Gln, and XRCC3 Thr241Met [12].

2.3. Statistical Analysis. Logistic regression analysis was carried out to calculate Odds Ratios (ORs) adjusted for different covariates (i.e., age, sex, smoking, and DNA polymorphisms, as appropriate) categorizing DNA adduct levels by RAL median value (above/below 0.1 DNA adducts per $10^{8} \mathrm{nn}$ ). A multiple regression analysis has also been performed grouping individuals according to the number of at risk alleles. A $P$-value less than or equal to $5 \%$ was considered significant. All the analyses were performed by the statistical package SPSS.

\section{Results and Discussion}

Genotype and allele frequencies were calculated by counting, and genotype distributions were in Hardy-Weinberg equilibrium. Genotype frequencies were, respectively: XRCC1 Arg194Arg $=88.8 \%, \operatorname{Arg} 194 \operatorname{Trp}=11.2 \%$, XRCC1 Arg399Arg $=38.5 \%$, Arg399Gln = 49\%, Gln399Gln = 12.5\%, XRCC3 Thr241Thr $=40 \%$, Thr241Met $=41 \%$, and Met241Met $=$ 19\%, in keeping with those reported previously [9].

Characteristics of the study population are summarized in Table 1. PBL DNA adducts were increased in former and current smokers in respect to nonsmokers. The highest levels of DNA adducts were detected in individuals that reported to smoke for more than 40 years. A slightly increment of DNA damage was observed in benign lung disease and lung cancer patients in respect to controls.

Multiple regression analysis shows an increased frequency of PBL DNA adducts in smokers for more than 40 years $(\mathrm{OR}=5.28,95 \%$ confidence interval (C.I.) 1.00-27.72, $P=.049)$. A significant trend with increasing number of smoked cigarettes was found $(P$ for trend $<.05)$. After the previous cited adjustments, no differences were observed comparing controls with benign lung diseases and lung cancer patients.

When the associations of DNA adducts with DNA polymorphisms were considered, a null association with XRCC1 Arg194Trp and Arg388Gln polymorphisms was found $(\mathrm{OR}=4.08,95 \%$ C.I. $0.77-21.48, P=.098$ and $\mathrm{OR}=1.32,95 \%$ C.I. $0.34-5.18 ; P=.689$, resp.). Conversely, a statistically significant inverse effect was observed with XRCC3 Thr241Met polymorphism $(\mathrm{OR}=0.17$, 95\% C.I. 0.05-0.61, $P=.006)$.

Then, we investigated the combination of the variant allele/s of XRCC1 Arg194Trp and Arg399Gln polymorphisms with the wild type allele of XRCC3 Thr241Met. 
TABLE 1: Means of DNA adducts \pm standard error (SE) for different variables considered in the study plus the parameter estimates of the multivariate regression model.

\begin{tabular}{|c|c|c|c|c|c|}
\hline & $N^{\mathrm{a}}$ & Means $^{\mathrm{b}} \pm$ S.E. & Odds Ratio & C.I. & $P$-value \\
\hline \multicolumn{6}{|l|}{ Gender } \\
\hline Woman ${ }^{\mathrm{c}}$ & 31 & $1.2 \pm 0.3$ & 1 & & \\
\hline Male & 73 & $1.3 \pm 0.2$ & 0.65 & $0.19-2.16$ & .480 \\
\hline \multicolumn{6}{|l|}{ Age (years) } \\
\hline Per unit & 104 & $1.3 \pm 0.2$ & 1.02 & $0.97-1.06$ & .516 \\
\hline \multicolumn{6}{|l|}{ Smoking habit } \\
\hline Nonsmoker ${ }^{\mathrm{c}}$ & 21 & $0.8 \pm 0.4$ & 1 & & \\
\hline Former smoker & 44 & $1.0 \pm 0.3$ & 1.60 & $0.39-6.58$ & .517 \\
\hline Smoker $<40$ years & 11 & $1.5 \pm 0.7$ & 2.38 & $0.41-13.90$ & .336 \\
\hline Smoker $\geq 40$ years & 27 & $2.0 \pm 0.5$ & 5.28 & $1.00-27.72$ & .049 \\
\hline \multicolumn{6}{|l|}{ Status } \\
\hline Controls $^{c}$ & 40 & $1.0 \pm 0.3$ & 1 & & \\
\hline Benign lung disease & 30 & $1.3 \pm 0.4$ & 0.93 & $0.28-3.03$ & .898 \\
\hline Lung cancer & 34 & $1.5 \pm 0.4$ & 1.17 & $0.39-3.47$ & .783 \\
\hline \multicolumn{6}{|l|}{ XRCC1 Arg194Trp } \\
\hline $\mathrm{Arg} / \mathrm{Arg}^{\mathrm{C}}$ & 87 & $1.1 \pm 0.2$ & 1 & & \\
\hline Arg/Trp & 11 & $2.6 \pm 1.1$ & 4.08 & $0.77-21.48$ & .098 \\
\hline \multicolumn{6}{|l|}{ XRCC1 Arg399Gln } \\
\hline $\operatorname{Arg} / \operatorname{Arg}^{\mathrm{c}}$ & 37 & $0.9 \pm 0.2$ & 1 & & \\
\hline Arg/Gln & 47 & $1.4 \pm 0.3$ & 0.93 & $0.36-2.39$ & .882 \\
\hline $\mathrm{Gln} / \mathrm{Gln}$ & 12 & $1.8 \pm 1.0$ & 1.32 & $0.34-5.18$ & .689 \\
\hline \multicolumn{6}{|l|}{ XRCC3 Thr241Met } \\
\hline Thr/Thrc & 40 & $1.5 \pm 0.4$ & 1 & & \\
\hline Thr/Met & 41 & $1.2 \pm 0.3$ & 0.38 & $0.15-0.97$ & .043 \\
\hline Met/Met & 19 & $0.7 \pm 0.4$ & 0.17 & $0.05-0.61$ & .006 \\
\hline \multicolumn{6}{|l|}{ Number of risk alleles } \\
\hline $0-1^{\mathrm{c}}$ & 25 & $0.8 \pm 0.4$ & 1 & & \\
\hline 2 & 31 & $1.0 \pm 0.3$ & 0.92 & $0.31-2.69$ & .877 \\
\hline $3-4$ & 38 & $2.0 \pm 0.5$ & 4.1 & $1.28-13.09$ & .009 \\
\hline
\end{tabular}

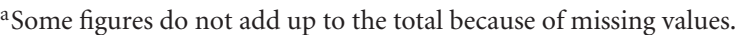

${ }^{\mathrm{b}}$ Levels per $10^{8}$ normal nucleotides.

${ }^{c}$ Reference level.

The choice was based on the different association of XRCC1 and XRCC3 polymorphisms with lung cancer risk, for example, positive for XRCC1 Arg194Trp and Arg399Gln and negative for XRCC3 Met241Met [9, 16, 17]. The analysis of the effect of different combinations of DNA repair single nucleotide polymorphisms on DNA adducts has been performed under the assumption that the combination of different polymorphisms can have additive or more than additive effects.

When the study population was categorized in base to the number of risk alleles, the levels of DNA adducts were statistically significantly increased in individuals bearing three-four risk alleles $(\mathrm{OR}=4.1$ 95\% C.I. 1.28-13.09, $P=$ .009). A significant association with smoking was noticed in smokers for more than 40 years carrying 3-4 risk alleles $(\mathrm{OR}=36.38,95 \%$ C.I. $1.17-1132.84, P=.040)$. A not statistically significant increment of lung cancer risk was observed in the same group ( $\mathrm{OR}=4.54,95 \%$ C.I. $0.33-62.93$, $P=.259)$. A significant trend with increasing the number of risk alleles was also observed ( $P$ for trend $<.05$ ). Any association with benign lung diseases was not found.

Tobacco smoking is recognised as the primary preventable cause of human cancer. Therefore, many studies have explored the influence of smoking on the levels of DNA adducts in nucleated blood cells in order to identify an early and sensitive biomarker of effective intake of tobacco carcinogens [18].

In our study, we have analyzed PBLs as surrogate and more accessible tissues than bronchial biopsies, and we compared the levels of DNA adducts in patients with lung cancer in respect to those with benign lung diseases and controls. Our aim was to evaluate whether the levels of 
TABLE 2: Means of DNA adducts \pm standard error (SE) case-control status considering the number of DNA repair risk alleles plus the parameter estimates of the multivariate regression model.

\begin{tabular}{|c|c|c|c|c|c|}
\hline & $N^{\mathrm{a}}$ & Means $^{\mathrm{b}} \pm$ S.E. & Odds Ratio & C.I. & $P$-value \\
\hline \multicolumn{6}{|l|}{ 0-1 risk alleles } \\
\hline \multicolumn{6}{|l|}{ Smoking habit } \\
\hline Nonsmoker ${ }^{\mathrm{c}}$ & 6 & $1.7 \pm 1.5$ & 1 & & \\
\hline Former smoker & 12 & $0.4 \pm 0.1$ & 0.08 & $0.00-9.76$ & .302 \\
\hline Smoker $<40$ years & 2 & $0.3 \pm 0.2$ & 0.33 & $0.00-67.26$ & .686 \\
\hline Smoker $\geq 40$ years & 5 & $1.3 \pm 1.1$ & 0.16 & $0.00-27.05$ & .480 \\
\hline \multicolumn{6}{|l|}{ Status } \\
\hline Controls $^{c}$ & 13 & $1.3 \pm 0.7$ & 1 & & \\
\hline Benign lung disease & 4 & $0.4 \pm 0.1$ & 1.23 & $0.08-19.30$ & .884 \\
\hline Lung cancer & 8 & $0.5 \pm 0.2$ & 0.43 & $0.05-4.00$ & .458 \\
\hline \multicolumn{6}{|l|}{2 risk alleles } \\
\hline \multicolumn{6}{|l|}{ Smoking habit } \\
\hline Nonsmoker ${ }^{\mathrm{c}}$ & 7 & $0.4 \pm 0.1$ & 1 & & \\
\hline Former smoker & 10 & $0.7 \pm 0.4$ & 2.46 & $0.12-50.98$ & .560 \\
\hline Smoker $<40$ years & 5 & $0.8 \pm 0.6$ & 0.86 & $0.03-28.37$ & .933 \\
\hline Smoker $\geq 40$ years & 9 & $1.7 \pm 0.6$ & 20.91 & $0.62-709.04$ & .091 \\
\hline \multicolumn{6}{|l|}{ Status } \\
\hline Controls $^{c}$ & 12 & $0.5 \pm 0.2$ & 1 & & \\
\hline Benign lung disease & 7 & $1.1 \pm 0.6$ & 1.11 & $0.12-10.00$ & .928 \\
\hline Lung cancer & 12 & $1.3 \pm 0.5$ & 2.39 & $0.25-22.62$ & .447 \\
\hline \multicolumn{6}{|l|}{ 3-4 risk alleles } \\
\hline \multicolumn{6}{|l|}{ Smoking habit } \\
\hline Nonsmoker ${ }^{\mathrm{c}}$ & 5 & $0.4 \pm 0.2$ & 1 & & \\
\hline Former smoker & 20 & $1.7 \pm 0.7$ & 9.47 & $0.52-173.16$ & .130 \\
\hline Smoker $\geq 40$ years & 9 & $2.9 \pm 1.3$ & 36.38 & $1.17-1132.84$ & .040 \\
\hline \multicolumn{6}{|l|}{ Status } \\
\hline Controls $^{c}$ & 12 & $1.5 \pm 0.6$ & 1 & & \\
\hline Benign lung disease & 15 & $2.1 \pm 0.9$ & 0.45 & $0.06-3.69$ & .460 \\
\hline Lung cancer & 11 & $2.3 \pm 1.1$ & 4.54 & $0.33-62.93$ & .259 \\
\hline
\end{tabular}

a Some figures do not add up to the total because of missing values.

${ }^{\mathrm{b}}$ Levels per $10^{8}$ normal nucleotides.

${ }^{\mathrm{c}}$ Reference level.

DNA adducts were associated with benign or malignant lung chronic diseases. The question of the utility of PBLs as a valid surrogate for a specific organ like lung, representing the events occurring in the target tissue, is still open [19]. Nevertheless, some studies have indicated that the use of PBLs such as a biological marker, may help in the identification of subjects at elevated risk [6-8]. PBLs are considered suitable to monitor environmental and occupational carcinogen exposure and to estimate the burden of DNA adducts in respiratory tissue $[5,20-22]$. In fact, increased amount of PBL DNA adducts have been found among subjects heavily exposed to air pollution [21]. The relationship with target tissue DNA adducts may vary between type of carcinogen and target tissue although significant correlations have been seen between the levels of DNA damage in PBLs and bronchial mucosa [20].
Uppermost, we have considered the effect of smoking on DNA adduct levels. Our findings show that the levels of DNA adducts of smokers were higher than those of former and nonsmokers. Our finding shows that PBL DNA adduct may reflect exposures to carcinogens, such as those contained in tobacco smoke better than other surrogate tissues, such as leukocyte DNA adducts. However, discrepant results have been also reported with PBLs [18]. This is probably due to methodical differences in the ${ }^{32} \mathrm{P}$ DNA postlabelling protocol applied from research laboratories.

Next results show that the effect of smoking on DNA damage was more marked in the subjects that reported to smoke for more than 40 years. Although detailed information on smoking history, for example, number of pack of cigarettes smoked per years was missing, our findings 
support the hypothesis that the formation of DNA adducts is significantly influenced by chronic carcinogen exposure. Furthermore, when study population was subgrouped for the number of risk alleles, a significant association with smoking was observed in the subjects carrying three or more risk alleles who reported to smoke for more than 40 years. Conversely, no effect of smoking was observed in smokers bearing one or less risk allele.

The contribution of duration of exposure to cigarette smoke has important implications for both research studies and prevention strategies. It has been shown that the age at first exposure and duration are associated influences to the levels of DNA adducts [23]. Smoking during adolescence has been shown to produce physiological changes leading to increased persistence of DNA adducts less, and subjects who begin smoking very early in life tend to be heavy smokers [23]. Two large epidemiological studies demonstrated that duration is more important than intensity of cigarette smoking in predicting lung cancer risk [24, 25]. Herein reported results support in part this hypothesis, thus shedding light on the mechanisms involved in the aetiology of smoking related cancers. It is likely that a plateau of the formation of DNA adducts is reached at these time points [5]. In fact, the persistence of DNA adducts in PBLs is less than one decade, which is the maximum lifespan for long-living lymphocytes.

Our next results show that DNA adduct levels were comparable in individuals with benign lung disease or with lung cancer and in controls. However, when specific combinations of variant alleles were investigated, a not significant increased lung cancer risk was observed in individuals bearing the same number of risk alleles.

In a meta-analysis of cancer and bulky DNA adducts [26], DNA damage has been reported to be predictive of lung cancer, particularly in smokers. In Veglia's metaanalysis, smokers presented a significant difference between lung cancer cases and controls, with patients having 83\% higher amount of DNA adducts than controls. We know that the interpretation of the meta-analysis is limited by the fact that in case-control studies, the level of biomarker may reflect the presence of cancer disease rather than its aetiology. However, an exception is represented by three cohort studies, in which DNA adducts have been found to be prospectively predictive of lung cancer outcome [68]. The importance of these studies is based on the fact that biomarker measurement in PBLs collected several years before cancer onset ruled out the possibility that the higher levels of DNA damage were reflecting metabolic changes associated with cancer.

No increment of DNA adducts has been found in subjects with different benign bronchial pathologies, such as COPD, asthma, and pneumoconiosis, characterized by important inflammatory processes in respect to controls. However, such inflammatory phenomena can influence DNA adduct levels in lung target cells by increasing the biologically effective dose of PAH [27]. This hypothesis is consistent with a previous case-control study where the levels of DNA adducts in individuals with inflammatory diseases were significantly higher than those of controls [28].
DNA damage primarily reflects exposures to carcinogens but is modulated by inherited and acquired susceptibilities. Age, gender, and life-style and dietary habits have been reported to influence levels of DNA adducts $[5,29,30]$. DNA adducts may be also influenced by the individual's ability to remove DNA adducts undergoing from interindividual variability [31]. Although the main pathway for removal of bulky DNA adducts is nucleotide excision repair, it has been shown that BER and DSB repair mechanisms may participate in bulky DNA adduct repair, supporting the association of XRCC1 and XRCC3 polymorphisms with such kind of DNA damage $[32,33]$. In this study we observed an effect of XRCC3 Thr241Met polymorphism on DNA adducts. Positive nonstatistically significant associations with XRCC1 Arg194Trp and Gln399Gln genotypes were found whereas an inverse significant association was detected in XRCC3 Met241Met carriers. Our findings are in keeping with previous studies showing that the variant alleles of the XRCC1 Arg399Gln polymorphism is associated with DNA adducts $[10,12,13]$. A recent pooled analysis has shown a protective effect conferred by XRRC3 241Met allele carriers against lung cancer [16]. However, other studies have reported higher levels of DNA damage in individuals with XRCC1 Arg194Arg and XRCC3 Met241Met genotypes [12, 33]. Our results suggest that case-control studies are more indicative for the determination of genetic susceptibility than cross-sectional studies.

To study the effect of different combinations of DNA repair single nucleotide polymorphisms on DNA adducts, we have investigated the combination of the variant allele/s of XRCC1 Arg194Trp and Arg399Gln polymorphisms with the wild type allele of XRCC3 Thr241Met. This was based on the different association of XRCC1 and XRCC3 polymorphisms with lung cancer risk, for example, positive for XRCC1 Arg194Trp and Arg399Gln and negative for XRCC3 Thr241Met [9, 16, 17, 34]. Our findings show that the combination of different polymorphisms can have additive effects on the levels of DNA adducts. In fact, when the number of risk alleles was analyzed, DNA adducts were higher in individuals carrying three-four risk alleles. Furthermore, when our population was categorized in base to the number of risk alleles, the association between smoking and lung cancer risk tended to be present in the same individuals bearing three-four risk alleles. Although statistical significances were seen in our analyses, our study is underpowered, and larger studies are needed to confirm the associations between DNA polymorphisms, cancer, and DNA adducts.

Furthermore, a previous report has shown that smoking is strong harmful factor that can eliminate the effect of DNA polymorphisms of DNA repair genes on lung cancer susceptibility [34]. Smoking could lead to cancer due to its toxic effect regardless of whether individuals have polymorphisms with low repair proficiency. Thus, the examination of the effect of different combinations of DNA polymorphisms for the prediction of lung cancer susceptibility could be more useful in nonsmokers exposed to relatively minor environmental factors. 


\section{Conclusions}

The results of the present study support the utilisation of PBLs as surrogate and more accessible tissues than bronchial biopsies. In fact, we have observed a stronger effect of smoking on DNA adducts of 40 years smokers. When study population was subgrouped for number of risk alleles, the association with smoking was concentrated in carriers of 34 risk alleles that reported to have smoked for more than 40 years. A nonsignificant increased lung cancer risk was observed in individuals bearing the same number of risk alleles. Our results suggest that analysis of risk alleles can predict the interindividual variation in DNA adduct levels observed in smokers and lung cancer cases.

\section{Acknowledgments}

This study was partially supported from the Associazione Italiana per la Ricerca sul Cancro (AIRC), Milan, Italy. The authors are grateful to Rosa Filiberti, Donatella Ugolini, Monica Neri, and Andrea Ardizzoni for their efforts in specimens collection.

\section{References}

[1] S. Dubey and C. A. Powell, "Update in lung cancer 2006," American Journal of Respiratory and Critical Care Medicine, vol. 175, no. 9, pp. 868-874, 2007.

[2] IARC, Monographs on the Evaluation of Carcinogenic Risks to Humans. Tobacco Smoke and Involuntary Smoking, IARC Scientific Publications, no. 83, IARC, Lyon, France, 1996.

[3] J. K. Wiencke, "DNA adduct burden and tobacco carcinogenesis," Oncogene, vol. 21, no. 48, pp. 7376-7391, 2002.

[4] L. E. Smith, M. F. Denissenko, W. P. Bennett et al., "Targeting of lung cancer mutational hotspots by polycyclic aromatic hydrocarbons," Journal of the National Cancer Institute, vol. 92, no. 10, pp. 803-811, 2000.

[5] M. Peluso, M. Ceppi, A. Munnia, R. Puntoni, and S. Parodi, "Analysis of 13 32P-DNA postlabeling studies on occupational cohorts exposed to air pollution," American Journal of Epidemiology, vol. 153, no. 6, pp. 546-558, 2001.

[6] D. Tang, D. H. Phillips, M. Stampfer et al., "Association between carcinogen-DNA adducts in white blood cells and lung cancer risk in the physicians health study," Cancer Research, vol. 61, no. 18, pp. 6708-6712, 2001.

[7] M. Peluso, A. Munnia, G. Hoek et al., "DNA adducts and lung cancer risk: a prospective study," Cancer Research, vol. 65, no. 17, pp. 8042-8048, 2005.

[8] H. Bak, H. Autrup, B. L. Thomsen et al., "Bulky DNA adducts as risk indicator of lung cancer in a Danish case-cohort study," International Journal of Cancer, vol. 118, no. 7, pp. 1618-1622, 2006.

[9] S. Zienolddiny, D. Campa, H. Lind et al., "Polymorphisms of DNA repair genes and risk of non-small cell lung cancer," Carcinogenesis, vol. 27, no. 3, pp. 560-567, 2006.

[10] D. Palli, A. Russo, G. Masala et al., "DNA adducts levels and DNA repair polymorphisms in traffic-exposed workers and a general population," International Journal of Cancer, vol. 94, pp. 121-127, 2001.
[11] G. Matullo, S. Guarrera, S. Caturan et al., "DNA repair gene polymorphisms, bulky DNA adducts in white blood cells and bladder cancer in a case control study," International Journal of Cancer, vol. 92, pp. 562-567, 2001.

[12] G. Matullo, D. Palli, M. Peluso et al., "XRCC1, XRCC3, XPD gene polymorphisms, smoking and 32P-DNA adducts in a sample of healthy subjects," Carcinogenesis, vol. 22, no. 9, pp. 1437-1445, 2001.

[13] G. Matullo, M. Peluso, S. Polidoro et al., "Combination of DNA repair gene single nucleotide polymorphisms and increased levels of DNA adducts in a population-based study," Cancer Epidemiology Biomarkers and Prevention, vol. 12, no. 7, pp. 674-677, 2003.

[14] G. Matullo, A. M. Dunning, S. Guarrera et al., "DNA repair polymorphisms and cancer risk in non-smokers in a cohort study," Carcinogenesis, vol. 27, no. 5, pp. 997-1007, 2006.

[15] M. Peluso, P. Srivatanakul, A. Munnia et al., "DNA adduct formation among workers in a Thai industrial estate and nearby residents," Science of the Total Environment, vol. 389, no. 2-3, pp. 283-288, 2008.

[16] R. J. Hung, D. C. Christiani, A. Risch et al., "International lung cancer consortium: pooled analysis of sequence variants in DNA repair and cell cycle pathways," Cancer Epidemiology Biomarkers and Prevention, vol. 17, no. 11, pp. 3081-3089, 2008.

[17] Z. Yin, B. Zhou, Q. He, M. Li, P. Guan, and X. Li, "Association between polymorphisms in DNA repair genes and survival of non-smoking female patients with lung adenocarcinoma," BMC Cancer, vol. 9, article 439, 2009.

[18] D. H. Phillips, "Smoking-related DNA and protein adducts in human tissues," Carcinogenesis, vol. 23, no. 12, pp. 1979-2004, 2002.

[19] A. Besaratinia, L. M. Maas, E. M. C. Brouwer, J. C. S. Kleinjans, and F. J. Van Schooten, "Comparison between smoking-related DNA adduct analysis in induced sputum and peripheral blood lymphocytes," Carcinogenesis, vol. 21, pp. 1335-1340, 2000.

[20] M. Peluso, M. Neri, G. Margarino et al., "Comparison of DNA adduct levels in nasal mucosa, lymphocytes and bronchial mucosa of cigarette smokers and interaction with metabolic gene polymorphisms," Carcinogenesis, vol. 25, no. 12, pp. 2459-2465, 2004.

[21] P. Vineis and K. Husgafvel-Pursiainen, "Air pollution and cancer: biomarker studies in human populations," Carcinogenesis, vol. 26, no. 11, pp. 1846-1855, 2005.

[22] L. Godderis, M. De Boeck, V. Haufroid et al., "Influence of genetic polymorphisms on biomarkers of exposure and genotoxic effects in styrene-exposed workers," Environmental and Molecular Mutagenesis, vol. 44, no. 4, pp. 293-303, 2004.

[23] J. K. Wiencke, S. W. Thurston, K. T. Kelsey et al., "Early age at smoking initiation and tobacco carcinogen DNA damage in the lung," Journal of the National Cancer Institute, vol. 91, no. 7, pp. 614-619, 1999.

[24] R. Doll and R. Peto, "Cigarette smoking and bronchial carcinoma: dose and time relationships among regular smokers and lifelong non-smokers," Journal of Epidemiology and Community Health, vol. 32, no. 4, pp. 303-313, 1978.

[25] W. D. Flanders, C. A. Lally, B.-P. Zhu, S. J. Henley, and M. J. Thun, "Lung cancer mortality in relation to age, duration of smoking, and daily cigarette consumption: results from cancer prevention study II," Cancer Research, vol. 63, no. 19, pp. 6556-6562, 2003. 
[26] F. Veglia, G. Matullo, and P. Vineis, "Bulky DNA adducts and risk of cancer: a meta-analysis," Cancer Epidemiology Biomarkers and Prevention, vol. 12, no. 2, pp. 157-160, 2003.

[27] P. J. Borm, A. M. Knaapen, R. P. Schins, R. W. Godschalk, and F. J. Schooten, "Neutrophils amplify the formation of DNA adducts by benzo[a]pyrene in lung target cells," Environmental Health Perspectives, vol. 105, pp. 1089-1093, 1997.

[28] C. Sacerdote, M. Peluso, A. Munnia, C. Malaveille, and P. Vineis, "The choice of controls in a case-control study on WBC-DNA adducts and metabolic polymorphisms," Biomarkers, vol. 5, no. 4, pp. 307-313, 2000.

[29] P. Vineis and F. Perera, "DNA adducts as markers of exposure to carcinogens and risk of cancer," International Journal of Cancer, vol. 88, no. 3, pp. 325-328, 2000.

[30] D. Palli, G. Masala, M. Peluso et al., "The effects of diet on DNA bulky adduct levels are strongly modified by GSTM1 genotype: a study on 634 subjects," Carcinogenesis, vol. 25, no. 4, pp. 577-584, 2004.

[31] M. Berwick and P. Vineis, "Markers of DNA repair and susceptibility to cancer in humans: an epidemiologic review," Journal of the National Cancer Institute, vol. 92, no. 11, pp. 874-897, 2000.

[32] E. Braithwaite, X. Wu, and Z. Wang, "Repair of DNA lesions induced by polycyclic aromatic hydrocarbons in human cellfree extracts: involvement of two excision repair mechanisms in vitro," Carcinogenesis, vol. 19, no. 7, pp. 1239-1246, 1998.

[33] Y. Wang, M. R. Spitz, Y. Zhu, Q. Dong, S. Shete, and $\mathrm{X}$. Wu, "From genotype to phenotype: correlating XRCC1 polymorphisms with mutagen sensitivity," DNA Repair, vol. 2, no. 8, pp. 901-908, 2003.

[34] Y. Tanaka, Y. Maniwa, V. P. Bermudez et al., "Nonsynonymous single nucleotide polymorphisms in DNA damage repair pathways and lung cancer risk," Cancer, vol. 116, pp. 896-902, 2010. 

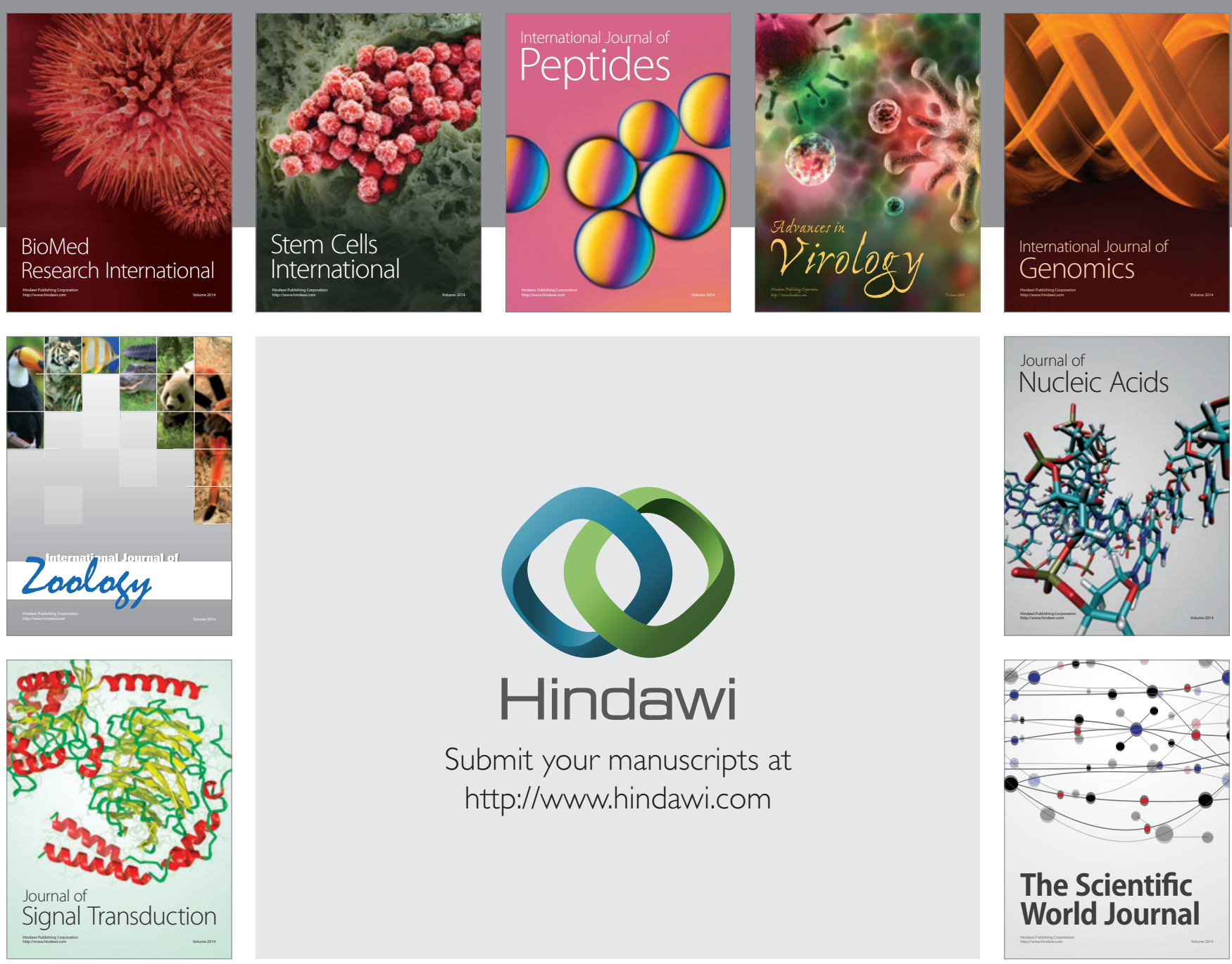

Submit your manuscripts at

http://www.hindawi.com
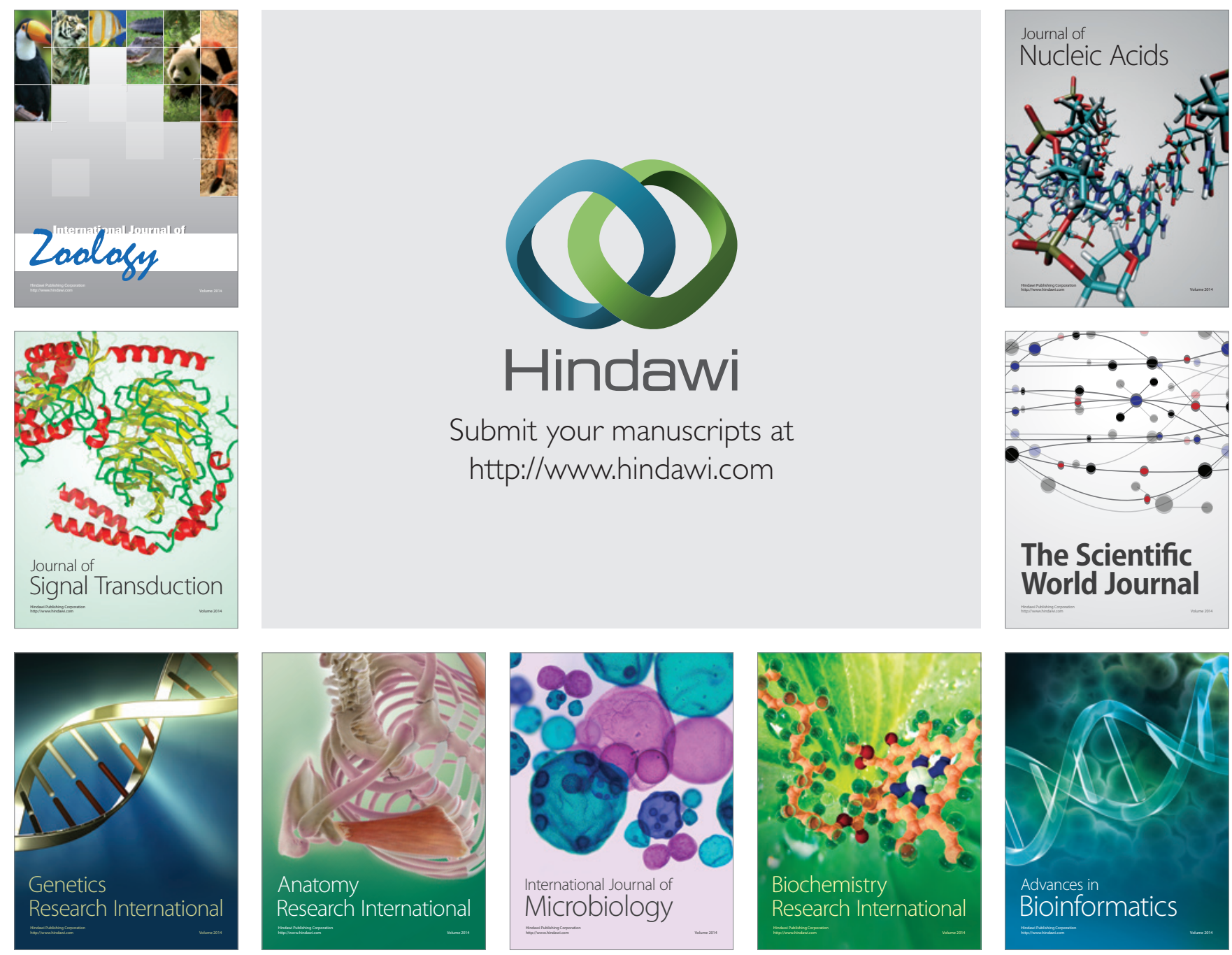

The Scientific World Journal
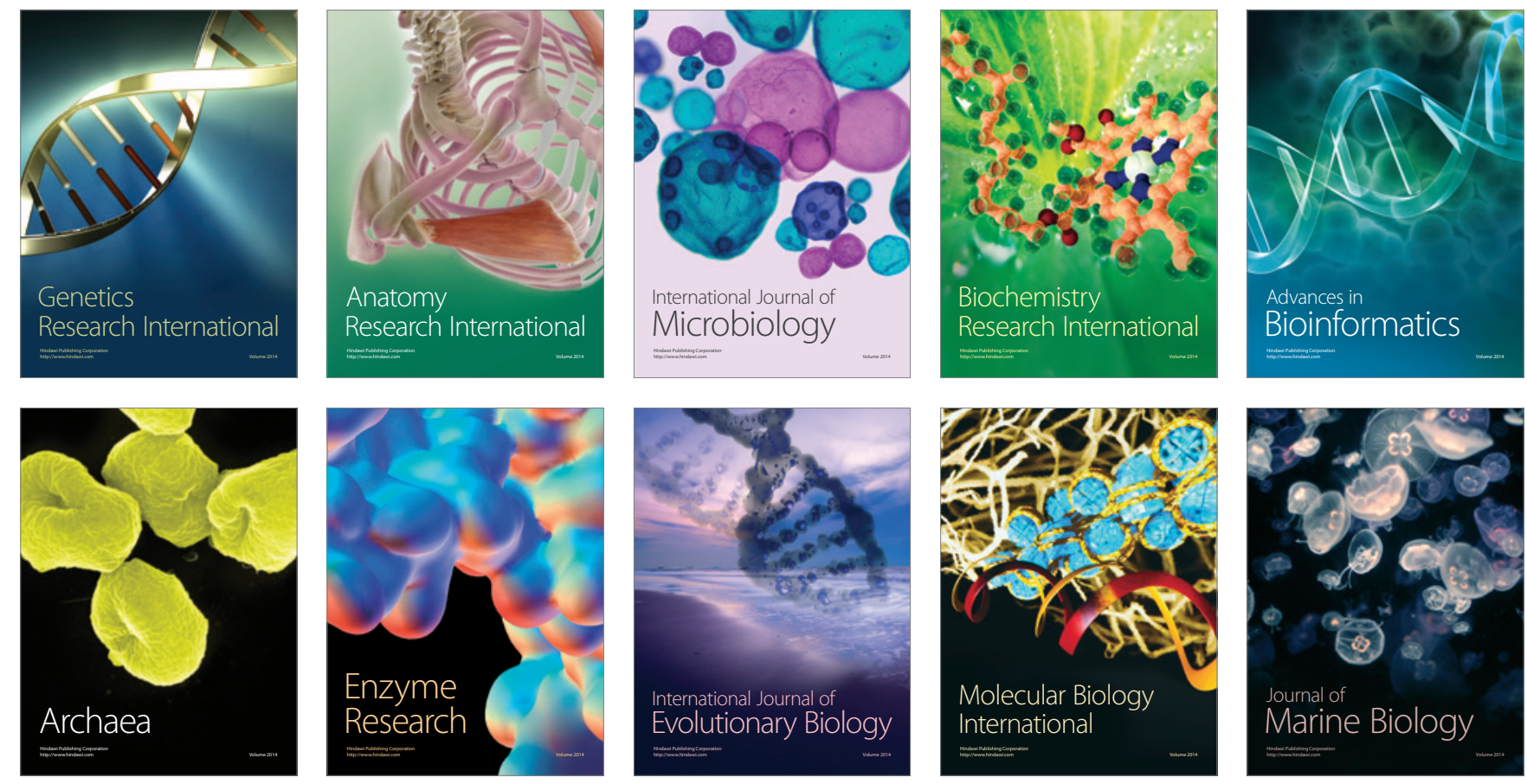